\title{
Análise das diferentes manifestações de cultura quanto aos cuidados em saúde bucal em moradores de região rural ribeirinha em Rondônia, Brasil
}

\author{
Analysis of different cultural aspects regarding oral health care \\ in citizens of the rural riverside region in Rondônia State, Brazil
}

Ricardo HenriqueAlves da Silva ${ }^{1}$

Roberta Francisca M artins de Castro ${ }^{2}$

José Roberto de $M$ agalhães Bastos ${ }^{3}$

Luis M arcelo deAranha Camargo ${ }^{4}$

${ }^{1}$ Área de Odontologia Legal, FaculdadedeOdontologiade Ribeirão Preto,

UniversidadedeSão Paulo. Avenida do Cafés/n, M onte Alegre. 14040-904 Ribeirão Preto SP.

ricardohenrique@usp.br

${ }^{2}$ Faculdades São Lucas.

${ }^{3}$ FaculdadedeO dontologia

deBauru, Universidade de

São Paulo.

${ }^{4}$ Instituto de Ciência

Biomédicas V, Universidade deSão Paulo.
Abstract This study aimed to assess the popular practices in oral health care on pathologies such as dental caries, periodontal disease and others, in Tabajara District, Rondonia State, Brazil as folklore has a great importance on cultural aspects of the Brazilian people, and can be considered a social and cultural aspect at the same time, reaching and influencing people in oral health care. It was based in a quanti-qual itativestudy, being the sample composed by 14 women and 6 men. The re search instrument comprehends a questionnaire with di rect and subjectivequestions, for data analysis in descriptive form. The results show a low knowledge about oral health aspects, as well as many alternative methods for "treatment" and "prevention" of oral diseases. There is a need of deeply knowledge about the target population on health programs, as many times it can insert cultural changes and, in order to avoid being destructives, must analyses the social-cultural structure of the community.

Key words Anthropology, D entistry, Public health
Resumo Esse estudo avaliou as práticas populares nos cuidados com a saúdebucal decorrentes de patologias como a cárie dentária, doença periodontal, entre outras, no distrito de Tabajara, Estado de Rondônia, Brasil, tendo em vista que o folclore é muito presente na cultura popular, sendo considerado um fato social e cultural, ao mesmo tempo atingindo e influenciando os cuidados quanto à saúde bucal. Realizou-se um estudo quanti-qualitativo, sendo a amostra composta por catorze mulheres e seis homens. 0 instrumento de pesquisa compreendeu um questionário, com questões objetivase subjetivas, sendo os dados analisados sob a forma descritiva. Observou-se um baixo nível de conhecimento em aspectos relacionados à saúde bucal nas pessoas analisadas, bem como uma variedade demétodos alternativos para "tratamento" e "prevenção" de afecções bucais. Concluiu-se que há necessidade de um conhecimento mais aprofundado da população-alvo dos programas em saúde, haja vista que introduzem, quase sempre, mudanças culturais, e para que sejam construtivos e não desintegradores, devem levar em conta a estrutura sociocultural da comunidade onde serão executados.

Pal avras-chave Antropologia, O dontologia, Saúde pública 
Introdução

A cárie dentária é uma doença infecciosa, transmissível emultifatorial. Sua manifestação depende da somatória de fatores relacionados diretamente, tais como a resistência do hospedeiro, dieta, microbiota presente na cavidade bucal e tempo ${ }^{1}$.

Em geral, a incidência de cárievem diminuindo no mundo todo, estando inclusive controlada em alguns países². Em menos de trinta anos, por exemplo, o índice médio de dentes com história de cárie nas crianças de doze anos (índice CPOD - dentes cariados, perdidos ou obturados) diminuiu de aproximadamente 12,0 para 1,44 dentes comprometidos por indivíduo no município de Bauru, Estado de São Paulo ${ }^{3}$.

Porém, a cárie continua sendo a doença de origem bucal mais prevalentena população, acometendo muitos indivíduos em todo o mundo, mesmo sendo uma doença possível de ser evitada à luz dos conhecimentos atuais, caracterizando-se, dessa forma, como um problema de saúde pública.

Embora não seja regra geral, há indícios de que, no Brasil e no mundo, as crianças mais afetadas por esta doença sejam provenientes degrupos populacionais desfavorecidos nos âmbitos político, econômico e social ${ }^{4-8}$. Tapias et al. ${ }^{9}$, em concordância com Sweeney et al..$^{10}$, sugeriram que as crianças provenientes de áreas carentes apresentam risco aproximadamente três vezes maior de serem acometidas pela doença cárie quando comparadas com crianças residentes em áreas economicamente mais favorecidas.

O Estado de Rondônia, onde se localiza a comunidade específica deste estudo, apresentava índice CPOD 3,5 para crianças de zero a catorze anos, em 199811. E, de acordo com os dados do M inistério da Saúde ${ }^{12}$, a Região Norte possui CPOD 3,13 aos doze anos de idade.

De acordo com a Organização Mundial de Saúde (OMS), algumas metas foram estabelecidas para serem atingidas até 0 ano 2000, dentre elas, $50 \%$ decrianças livres de cárieaos cinco anos de idade e índice CPOD, para crianças de doze anos, no máximo igual a três $(3,0)^{2}$.

Porém, de acordo com o relatório do levantamento das condições de saúde bucal, promovido em âmbito nacional pelo M inistério da Saú$\mathrm{de}^{12}$, o percentual de crianças livres de cárie para a região $\mathrm{N}$ orte foi de $24,15 \%$ para a idade dedoze anos. Além disso, aos doze anos deidade, O CPOD da região Norte foi 3,13 , enquanto que, para a mesma faixa etária, a média nacional foi de 2,78.
A principal diferença entre as regiões se encontra na distribuição dos componentes, com maior proporção de cariados ( $" \mathrm{C}$ " $=72,52 \%$ ) e perdi$\operatorname{dos}(" \mathrm{P}$ " $=11,50 \%$ ) na região N ortequando comparada com as regiões Sul ( $C$ " $=48,05 \% \mathrm{e}^{\prime \prime} \mathrm{P}$ " = $4,76 \%$ ) e Sudeste ( $" C$ " $=42,17 \%$ e "P" $=3,04 \%$ ) ou mesmo com as proporções nacionais ( $\mathrm{C}$ " = $58,27 \%$ e "P" $=6,47 \%$ ).

As regiões $\mathrm{N}$ ortee $\mathrm{N}$ ordeste também são responsáveis pelo maior volume de pessoas que nunca foram atendidas por um cirurgião-dentista ( $16,56 \%$ e $21,65 \%$, respectivamente), sendo que a consulta de rotina respondeu por apenas $23,18 \%$ da procura ao atendimento e a grande responsável pela busca foi mesmo a dor, representando $40,16 \%$ das razões para a consulta odontológica ${ }^{12}$

M esmo antes da divulgação dos dados do levantamento nacional, em um município do interior do Estado de Rondônia, M onte N egro (situado a $250 \mathrm{~km}$ da capital Porto Velho), uma equipe de alunos de graduação, pós-graduação e docentes da Faculdade de O dontologia de Bauru da Universidade de São Paulo, atuando tanto em zona urbana como em zona rural, em projeto de extensão universitária, observou um número elevado de dentes perdidos por cárie em todas as faixas etárias ${ }^{13}$.

Com base nesse fato, algumas necessidades foram despertadas na equipe de saúde, a partir do envolvimento com comunidades ribeirinhas e populações distantes de centros urbanos, no que se refere aos conhecimentos e cuidados em saúde bucal.

Sendo assim, tendo em vista que a antropologia aplicada à saúde investiga e explica as causas de doenças, cuidados, tratamentos e itinerários percorridos pelas pessoas quando estão enfermas, notou-se a importância de verificar, previamente à instalação de programas de saúde bucal, as influências biológicas e socioculturais no processo saúde-doença.

É importante ressaltar que, conforme Rosenthal ${ }^{14}$, a história da medicina popular é o passo inicial da história da medicina, buscando tratamento para cada mal específico ou uma maneira de prevenir os males e assegurar boa saúde. Assim, desde tempos imemoriais, o homem fez uso de elementos naturais ou mágicos para se proteger de doenças que supostamente eram causadas por espíritos malignos. E, como consequência, a medicina popular se desenvolveu em dois grandes campos: a natural e a baseada em práticas mágicas e religiosas, sendo observados relatos de práticas, tais como enrolar um dente de alho 
em um chumaço de algodão e colocar dentro do ouvido do lado contrário ao dente que dói; passar sobre 0 dente dolorido um algodão embebido em creolina; colocar a mão sobre o dente dolorido e rezar um Salve Rainha dedicada à N ossa Senhora do Desterro ${ }^{14}$.

É possível que tais práticas estejam presentes na população em questão, visto que apresenta como características baixa condição socioeconômica, falta de saneamento básico, ausência de assistência à saúde na maior parte do tempo, distância de centros urbanos que possibilitem o mínimo de cuidado em saúdebucal, dentreoutros ${ }^{15}$.

0 objetivo do presente estudo foi avaliar as práticas utilizadas no cuidado com a saúde bucal pela população do distrito de Tabajara, em Rondônia, residente às margens do Rio M achado.

\section{M aterial emétodos}

Este estudo foi aprovado pelo Comitê de Ética em Pesquisa da Faculdade de Odontologia de Bauru. Todos os participantes da pesquisa assinaram o termo de consentimento livree esclarecido, após as devidas explicações referentes aos procedimentos a que seriam submetidos.

0 universo compreendeu a população residente no distrito de Tabajara $(n=146)$, pertencente ao município de M achadinho D'O este, Estado de Rondônia, localidade situada às margens do Rio M achado. Adotou-se como fatores de inclusão na amostra os seguintes critérios: moradores maiores de dezoito anos e pai e/ou mãe de família. Deste modo, a amostra foi composta por vinte sujeitos, dos quais catorze eram mulheres e seis eram homens.

0 estudo foi do tipo quanti-qualitativo e 0 instrumento da pesquisa constou da aplicação de um questionário composto de questões objetivas e de entrevistas concedidas a respeito das "técnicas" utilizadas, a fim deilustrar estetrabaIho e mostrar a riqueza cultural da população.

0 questionário foi composto pelas seguintes perguntas: (1) 0 que você faz quando tem dor dedente? (2) Acha normal ter o denteescurecido, manchado, furado? (3) 0 quea comunidade costuma fazer quando os dentes de leite estão caindo nas crianças? (4) Você sabe onde nasce o primeiro dente permanente, dente de adulto?

0 roteiro para entrevista, abordou as mesmas questões, mas permitindo ao sujeito da pesquisa uma mai or liberdade nas respostas, sendo composto conforme transcrito a seguir:

1. 0 que você faz quando tem dor de dente?
Você conhece algum tratamento?

2. Acha normal ter o dente escurecido/manchado/furado? Por que você acha que o dente fica assim? Você sabe de al guma coisa que possa ser feita quando isso acontece?

3. 0 que a comunidade costuma fazer quando os dentes de leite estão caindo nas crianças?

4. 0 que faz quando os dentes permanentes estão nascendo?

Simultaneamente, foram real izados pela equipe presenteno local instrução sobre higieneoral, distribuição dekitscontendo escovas, fio dental e dentifrício, bem como a realização de procedimentos curativos, basicamente ART (tratamento restaurador atraumático ${ }^{16}$, raspagens periodontais e exodontias.

Todos os atendimentos odontológicos executados respeitaram as normas vigentes de controle deinfecção; porém, não havia cadeirasodontológicas, sendo os pacientes acomodados em cadeiras escolares e a equipe profissional trabaIhando em pé, na maioria das vezes.

0 trabalho curativo da equipe odontológica executou, em um período de três dias, para a população interessada, 42 consultas odontológicas, sendo os procedimentos compostos por 41 exodontias, 31 escavações em massa e preenchimento com IRM, dezoito restaurações com ionômero de vidro pela técnica conhecida como ART e doze raspagens periodontais.

Os resultados foram analisados de forma descritiva, porém permitindo aos sujeitos da pesquisa que relatassem suas experiências e conhecimentos quanto a tratamentos caseiros e simpatias em afecções de saúde bucal.

\section{Resultados}

$\mathrm{N}$ a questão referente ao que faz quando tem dor de dente, $40 \%$ dos sujeitos responderam queutilizam medicamentos tradicionais (principalmente analgésicos), 50\% utilizam medicamentos alternativos (chás, simpatias, entre outros) e $10 \%$ procuram serviços de saúde para realizar a exodontia do elemento dentário. Sobre se acha normal ter o dente escurecido, manchado ou furado, $50 \%$ consideram como um fato que não é normal, 35\% não souberam responder, $15 \%$ consideram normal.

Quando questionados a respeito da estraté gia frente ao fato de os dentes decíduos (apresentados aos sujeitos da pesquisa como dentes de leite) ficarem "moles" (processo de esfoliação), 80\% dos entrevistados responderam que 
extraem o dente em casa mesmo, 15\% não fazem nada, apenas aguardam o dente "cair" sozinho, e $5 \%$ levam a criança ao cirurgião-dentista.

Quando indagados sobre qual o primeiro dente permanente (apresentado como dente de adulto, que não troca) a aparecer na boca da criança, 70\% ressaltaram que são os dentes da frente, $25 \%$ não souberam responder, $5 \%$ responderam que são os dentes do fundo.

Dentro das entrevistas, optou-se por transcrever alguns trechos das falas dos sujeitos da pesquisa a respeito das receitas ou simpatias transmitidas pelos moradores, quando há o acometimento de problemas de ordem bucal:

. D or de dente: Bochecho com óleo de copaíba, etambém álcool com a folha do jaborandi colocado com um algodão.

Pega o sabugo de milho, queima ele, aí põe ele para ferver, depois, enquanto está morno, você coloca uma colher de polvilho dentro, aí mexe, aí põe uma pitadinha de sal, aí mexe, deixa descansar e faz a bochechada.

Faz o chá da rama de batata, deixa esfriar um pouco e bochecha.

U m garimpei ro passou para mim que para dor de dente vocêpega o sabugo de milho e queima até virar cinzas. Aquela cinza branca, depois de esfriar um pouco, é colocada no toco do dente, aí sara.

Colocar um al ho no algodão e col ocar no dente. Fica um dia, depois tira, lava e passa a dor.

Conheci essa simpatia pouco tempo atrás e só uso ela. Pegava uma aranha, prendia ela com um pau e cuspia na boca dela. Depois disso, o dente não doeu mais mesmo.

- Troca de dentes (dentes decíduos para dentes de permanentes): A genteia no rio, pegava uns caranguejinhos da beira, aí arrancava os dentinho dele, embolsava eamarrava no pulso da criança. Aí os dentes nascem sem problema, uma beleza.

- Extração de dentedecíduo: Amarra uma cordinha e dá um puxão. D epois põe sal para sarar logo. M inha mãe usava comigo e eu uso com os meus filhos.

\section{Discussão}

É de suma importância ressaltar, inicialmente, a condição de vida no distrito de Tabajara, foco da pesquisa. Trata-se de uma localidade a sessenta quilômetros do município de Machadinho D'O este, local mais próximo a contar com serviços de saúde. A estrada que liga as duas localidades não apresenta asfalto e, na época de chuvas, fica praticamente impossível realizar a viagem, a não ser em carros com tração nas quatro rodas.

Por isso, apesar da curta distância, a viagem geralmente demora cerca de três horas. A maioria da população não se desloca rotineiramente para Machadinho D'O este, haja vista não ter condições financeiras para pagar a passagem de ônibus. Além disso, a comunidade estudada apresenta uma dieta alimentar baseada na pesca, plantio de mandioca e pequenas criações (galinha e gado), além de frutas locais e da caça. Estas condições podem justificar, em parte, a variada gama de "tratamentos" al ternativos utilizados pelos moradores, haja vista não existir nenhum tipo de serviço de saúde instalado na localidade.

Dentre as folhas utilizadas pelos moradores, observamos, de acordo com Teske e Trentini ${ }^{17}$, as seguintes propriedades:

. Jaborandi: trata-se de um pequeno arbusto quepode atingir atédois metros de altura. Como ações comprovadas, é um estimulante do peristaltismo e da secreção salivar, além de combater a febre;

- Alho: tem ação antisséptica, analgésica, antiinflamatória e antibacteriana;

- Copaíba: o óleo de copaíba constitui um material resinoso extraído por meio de incisão no tronco da copaibeira. Possui ação antisséptica ecicatrizante.

0 uso de recursos disponíveis na comunidade do distrito de Tabajara vai ao encontro dos dizeres de Enwonwu ${ }^{18}$ que, ao analisar a condição da saúde bucal na África, explicita que os métodos de prevenção devem ser obtidos localmente e devem ser de fácil acesso e igualmente aceitáveis para os usuários.

Esse estudo é o foco de ação da antropologia cultural, que tem como característica o estudo dos seres humanos como seres culturais e fazedores de cultura, investigando as culturas humanas no tempo e no espaço, suas origens e desenvolvimento ${ }^{19}$.

Porém, para que tal fato venha ocorrer, énecessário superar a relação unívoca e autoritária normalmente presente nos programas de saúde, em que a população é reduzida à condição de mero objeto recebedor de serviços, sem expectativa ou vontade própria, ou seja, inserir aspectos de natureza cultural e antropológica que determinam os comportamentos com relação à saúde bucal ${ }^{20}$.

Na mesma vertente, M israchi e Sáez, citados por Unfer e Saliba ${ }^{21}$, salientam que é necessário considerar os estilos de vida e as formas de viver das populações a quem são dirigidas as ações de saúde, pois no campo da cultura popular, os co- 
nhecimentos, os valores, as crenças e as práticas se vinculam com fatores biológicos, econômicos e sociais.

E, a fim de superar as barreiras entre os profissionais de saúde e a população-alvo do programa, uma das soluções estaria condicionada à obtenção de uma fórmula que fizesse com que o povo aceitasse mel hor os conceitos e práticas sanitárias que Ihe são recomendados; um melhor conhecimento dos fatores humanos traria, certamente, contribuição para o êxito de programas sanitários.

0 trabalho de Unfer eSaliba ${ }^{22}$, no qual foram entrevistadas 389 pessoas com idade entre quinze 79 anos, no município de Santa M aria (RS), a respeito de práticas cotidianas em saúde bucal, revelou que $65,8 \%$ dos entrevistados consideraram que a cárie dentária pode ser evitada através do autocuidado, enquanto que para $36,5 \%$ o cirurgião-dentista tem um papel significativo nesse processo. Verificou-setambém que $64,7 \%$ acreditam que os dentes podem resistir durante todo o tempo de vida, enquanto que 30,8\% não crêem na durabilidade dos dentes.

No estudo desenvolvido por M enino e Bije$11 \mathrm{a}^{23}$, no qual se analisou o conhecimento com relação à própria saúde bucal em núcleos de saúdedeBauru, 53,3\% dos sujeitos de pesquisa disseram que nem todas as pessoas terão seus dentes estragados e $56 \%$ responderam que os dentes permanentes nascem para durar a vida toda.

Roch ${ }^{24}$ realizou estudo na Bahia eencontrou que $64,5 \%$ das gestantes entrevistadas consideram que as pessoas terão seus dentes estragadose $62,2 \%$, que os dentes permanentes não têm capacidade para resistir durante a vida da pessoa.

No presente estudo, $15 \%$ das pessoas entrevistadas consideram normais as alterações no dente (decorrentes, principalmente, da doença cárie) e quase a totalidade não sabe indicar qual o primeiro dentepermanentea irromper na boca, o que pode ocasionar grandes problemas, haja vista a importância do primeiro molar permanente como chave de oclusão e a perda precoce do mesmo.

Quanto ao público predominante a participar do estudo, $70 \%$ dos sujeitos da pesquisa pertencem ao gênero feminino e 30\% ao gênero masculino, assim como registrado em outros estudos em serviços de saúde ${ }^{22,25,26}$, o que poderia ser explicado pelo fato de as mulheres permanecerem em casa, estando, portanto, mais acessíveis, além de serem responsáveis pelos cuidados de saúde dos filhos, haja vista que a amostra foi selecionada por conveniência.

O conhecimento dos aspectos culturais da população éimportante para os sanitaristas, pois nem sempre as verdadeiras razões são apresentadas pela população para explicar a sua resistência ou falta de colaboração com os programas de saúde pública, haja vista que ao existir choque com valores culturais importantes do grupo, principalmente os de ordem religiosa ou ética, os indivíduos, em geral, não os referem aos sanitaristas ${ }^{27}$.

\section{Conclusão}

Concluiu-se que, na população do distrito de Tabajara, em Rondônia, residente às margens do Rio Machado, há uma diversidade de práticas utilizadas nos cuidados com a saúde bucal, sendo que o conhecimento e compreensão da cultura local obtidos poderão possibilitar a elaboração de um efetivo plano de promoção de saúde bucal, objetivando uma melhor acolhida do projeto pela população, minimizando as diferenças culturais com os profissionais de saúde.

\section{Colaboradores}

RHA Silva trabalhou na concepção, execução e compilação de dados da pesquisa, assim como na organização e redação final. RFM Castro colaborou na coleta de dados. JRM Bastos colaborou na organização do projeto de pesquisa eviabilização do mesmo. LM A Camargo coordenou as atividades de campo e colaborou na organização do texto final. 


\section{Referências}

1. Newbrun E. Cariologia. São Paulo: Santos; 1988.

2. Pinto VG. Saúde bucal coletiva. 4a ed. São Paulo: Santos; 2000.

3. Ramires I, Bastos JRM, Bastos RS, Sales-Peres SHC, Castro RFM, Cardoso MTV. Crianças livres de cárie, entre 7 e 12 anos de idade, Bauru, 2001. Pesqui Odontol Bras 2002; 16(Supl.):24.

4. Baldani MH, Narvai PC, Antunes JLF. Cárie dentária e condições sócio-econômicas no Estado do Paraná, Brasil, 1996. Cad Saude Publica 2002 18(3):755-763.

5. Bastos JRM, Magalhães SA, Silva RHA. Levantamento epidemiológico de cárie dentária no município de Poço Fundo, Minas Gerais, nos anos de 1999 e 2003. Arqu O dontol 2006; 42(2):124-132.

6. Freire M CM, M elo RB, Silva SA. Dental caries prevalence in relation to socioeconomic status of nursery school children in Goiânia-GO, Brazil. Community Dent Oral Epidemiol 1996; 24:357-361.

7. Maltz M, Barbachan BS. Relação entre cárie, gengivite e fluorose e nível socioeconômico em escolares. Rev. Saude Publica 2001; 35(2):170-176.

8. Sweeney PC, Gelbier S. The dental health of preschool children in a deprived urban community in Glasgow. Community Dent Health 1999; 16(1): 22-25.

9. Tapias MA, De-Miguel G, Jiménez-Garcia $R$ Gonzalez A, Domínguez V. Incidence of caries in an infant population in Mostoles, Madrid. Evaluation of a preventive program after 7.5 years of follow-up. Int J Paediatr Dent 2001; 11(6): 440-446.

10. Sweeney PC, Nugent Z, Pitts NB. Deprivation and dental caries status of 5-year-old children in Scotland. Community Dent Oral Epidemiol 1999; 27(2):152-159.

11. Governo do Estado de Rondônia. [site da Internet] [acessado 2005 set]. Disponível em: http://www. rondonia.ro.gov.br/prefeituras/Indicadores/M onte N egro.htm

12. Brasil. M inistério da Saúde. Secretaria de Atenção à Saúde. Departamento de Atenção Básica. Projeto SB Brasil 2003: condições de saúde bucal da população brasileira 2002-2003: resultados principais. Brasília: Ministério da Saúde; 2004.

13. Silva RHA, Castro RFM, Yaedú RYF, Caldana ML, Camargo, LM A, Bastos Jr M. Análise descritiva do projeto de melhoria de saúde bucal da população de M onte Negro - Rondônia (Leste Amazônico). In: Anais do V Encontro Científico da Pós-Graduação do HRAC-USP; 2003 nov 21-23; Bauru.
14. Rosenthal E. Os dentes e o folclore no Brasil. Brasil: Yasyama; 1998.

15. Silva RHA, Castro RFM, Caldana ML, Sales-Peres A, Sales-Peres SH de C, Bastos JRM. Desafios em promoção de saúde bucal: abordagem antropológico-cultural e epidemiológica de população ribeirinha em RO. Braz Oral Res 2004; 18(Suppl.):29.

16. Frencken JE, Holmgren CJ. Tratamento restaurador atraumático. São Paulo: Santos; 2001.

17. Teske $M$, Trentini AMM . Herbarium: compêndio de fitoterapia. 4a ed. Curitiba: Herbarium Laboratório Botânico; 2001

18. Enwonwu CO. Expectativas de la sociedad en mate ria de salud bucal: respuesta del sistema de atención dental en África. Bol FDI 1989; (164):8-9.

19. Marconi MA, Presotto ZMN. Antropologia: uma introdução. 5a ed. São Paulo: Atlas; 2001.

20. Botazzo C. Democracia, participação popular e programas comunitários. Saúde em Debate 1986; 18:33-39.

21. Unfer B, Saliba O. Avaliação do conhecimento popular e práticas cotidianas em saúde bucal. Rev. Saude Publica 2000; 34(2):190-195.

22. Unfer B, Saliba O. Avaliação do conhecimento popular e práticas cotidianas em saúde bucal. Rev. Saude Publica 2000; 34(2):190-195.

23. Menino RTM, Bijella VT. Necessidades de saúde bucal em gestantes dos núcleos de saúde de Bauru. Conhecimentos com relação à própria saúde bucal. Rev Fac Odontol Bauru 1995; 3(1-4):5-16.

24. Rocha M CBS. Avaliação dos conhecimentos e das práticas em saúde bucal - gestantes do Distrito Sanitário Docente Assistencial Barra/Rio Vermelho - município de Salvador/BA [tese]. São Paulo (SP): Faculdade de Odontologia; 1993.

25. $M$ arcos B. Sistemas de atenção em O dontologia: vias de acesso. Rev Paul Odontol 1991; 13:2-14.

26. Vasconcellos MCC, Silveira FO. Conhecimento sobre a manutenção da própria saúde bucal em população que demanda centro de saúde. Rev Odontol UNESP 1989; 18:225-231.

27. Bastos JR de M, Ramires I, Aquilante AG. Antropologia Cultural: cultura, instinto e saúde. Bauru: FOBUSP; 2002

Artigo apresentado em 20/07/2007

Aprovado em 04/03/2008

Versão final apresentada em 16/05/2008 